\title{
Moving toward better health: exercise practice is associated with improved outcomes after spine surgery in people with degenerative lumbar conditions
}

\author{
Carolyn E. Schwartz, ScD \\ Roland B. Stark, MEd \\ Phumeena Balasuberamaniam, \\ HBSc \\ Mopina Shrikumar, HBSc \\ Abeer Wasim, MSc \\ Joel A. Finkelstein, MD, MSc \\ Presented at the 20th Annual Scientific \\ Conference of the Canadian Spine Society \\ conference, Feb. 26-29, 2020, Whistler, B.C.
}

Accepted Aug. 12, 2020

\section{Correspondence to: \\ C. Schwartz}

DeltaQuest Foundation, Inc.

31 Mitchell Rd

Concord MA 01742

carolyn.schwartz@deltaquest.org

DOI: $10.1503 /$ cjs. 010620
Background: Recovery and rehabilitation following surgery can take many months. Understanding what patients can do to facilitate recovery would be beneficial for spinal surgeons. This study sought to evaluate the impact of exercise practice, before and after surgery, on long-term outcomes of spine surgery in a robust clinical sample.

Methods: This prospective longitudinal cohort study included adult patients undergoing spinal surgery for degenerative spinal conditions. Patients were administered a survey that included preoperative and postoperative exercise practices and the following patient-reported outcome measures: the physical component score (PCS) and mental component score (MCS) of the Medical Outcomes Study 36-Item Short Form Survey (Rand-36), the Oswestry Disability Index (ODI) score, the Numeric Rating Scale (NRS) score for pain and the Patient-Reported Outcome Measurement Information System (PROMIS) Pain Interference Short Form score. Random effects models investigated the relationship of exercise, follow-up time and their interaction in predicting each patient-reported outcome measure over time, with and without sociodemographic covariates.

Results: There were 168 patients in the study sample with up to 12 months of follow-up data. Analysis revealed modest significant main effects of exercise on PCS, MCS, ODI and PROMIS scores and main effects of time on all outcomes. The exercise-by-time interaction was significant in predicting the trajectories of the ODI and MCS scores. When full models were adjusted for education and employment status, interaction effects were no longer significant, but exercise main effects remained significant for ODI score.

Conclusion: Patients who engage in exercise before and after spine surgery have better mental health and spine-specific recovery trajectories than those who do not. All health care providers should encourage patients to exercise while they are waiting for surgery within preoperative limitations and as soon as they are able after surgery and to continue this over the long term.

Contexte : Le rétablissement et la réadaptation postopératoires s'échelonnent parfois sur plusieurs mois. Comprendre ce que les patients peuvent faire pour faciliter leur rétablissement serait utile aux spécialistes de la chirurgie de la colonne vertébrale. Cette étude a voulu évaluer l'impact de la pratique d'exercices avant et après une chirurgie de la colonne vertébrale sur son issue à long terme dans un solide échantillon clinique.

Méthodes : Cette étude de cohorte longitudinale prospective a regroupé des patients adultes qui devaient subir une chirurgie de la colonne vertébrale pour des maladies dégénératives. Les patients ont été invités à répondre à un questionnaire qui portait entre autre sur la pratique d'exercices pré- et postopératoires et sur les paramètres autorapportés suivants : scores aux composantes physique (PCS) et mentale (MCS) du questionnaire SF-36 (Medical Outcomes Study 36-Item Short Form Survey [Rand-36]), à l'échelle d'incapacité d'Oswestry (ODI), à une échelle d'évaluation numérique (ÉÉN) de la douleur et au questionnaire court PROMIS (Patient-Reported Outcome Measurement Information System) sur l'interférence de la douleur. Des modèles à effets aléatoires ont permis d'analyser les liens entre l'exercice, la durée du suivi et leur interaction pour ce qui est de prédire chacun des paramètres autorapportés au fil du temps, avec et sans les covariables sociodémographiques.

Résultats : L'étude a regroupé 168 patients et les données pour un suivi allant jusqu'à 12 mois. L'analyse a fait état d'effets majeurs significatifs 
modestes de l'exercice sur les paramètres PCS, MCS, ODI et PROMIS et d'effets majeurs du temps sur tous les paramètres. L'interaction entre exercices et durée du suivi a été significative pour prédire la trajectoire des scores ODI et MCS. Lorsque les modèles intégraux ont été ajustés pour tenir compte du niveau de scolarité et du statut professionnel, les effets de l'interaction n'étaient plus significatifs, mais les effets majeurs de l'exercice sont demeurés significatifs pour le score ODI.

Conclusion : Les patients qui ont fait des exercices avant et après une chirurgie de la colonne vertébrale ont présenté des trajectoires plus favorables au plan de la santé mentale et du rétablissement de leur colonne vertébrale comparativement à ceux qui n'avaient pas fait d'exercices. Tous les professionnels de la santé devraient encourager les patients à faire des exercices pendant qu'ils attendent leur chirurgie en tenant compte de leurs limites préopératoires, à les reprendre le plus rapidement possible après la chirurgie et à les maintenir à long terme.

E xercise is a health-enhancing behaviour, and there is a broad evidence base suggesting its benefits for physical and mental health. ${ }^{1}$ The benefits of exercise have paralleled those of drug therapy in protecting against mortality for cardiovascular conditions and diabetes ${ }^{2}$ and in reducing anxiety and depression in older adults. ${ }^{3}$

Exercise is a reserve-building activity ${ }^{4}$ that people can do independently at relatively low $\operatorname{cost}^{5}$ and across the disability spectrum. ${ }^{6}$ It can have collateral benefits in terms of social support, ${ }^{7}$ cardiovascular health ${ }^{8}$ and cognitive function in both healthy ${ }^{9}$ and chronically ill populations. ${ }^{10}$ The impact of exercise on cognitive function is particularly important in terms of optimizing a range of executive functions. ${ }^{9,11}$ Consequently, exercise enhances cortical plasticity ${ }^{12}$ and brain maintenance. ${ }^{13}$

Exercise is widely prescribed as symptomatic treatment of acute and chronic back pain; however, the level of the evidence for individual studies is low. ${ }^{14,15}$ Exercise is often operationalized in terms of physiotherapy interventions, such as segmental stabilizing exercises; ${ }^{16}$ mobilization, motor control or traction exercises; ${ }^{17}$ back flexibility and strength exercises; ${ }^{18}$ or exercise tolerance on a treadmill. ${ }^{19}$ The value of such prescribed and overseen exercise regimens in spinal conditions is felt to be in large part due to enhancing dynamic stabilizers of the spine. ${ }^{16}$ Exercise is also valuable in that it has the collateral benefit of facilitating weight loss, which has also been shown to play a role in spinal health. ${ }^{20}$ Several randomized trials have sought to determine the impact of professional support and oversight of graded active exercise after surgery, ${ }^{21}$ vigorous medical exercise rehabilitation therapy after surgery ${ }^{22}$ and rehabilitation therapy before and after surgery. ${ }^{23}$ Overall, these trials have not documented a long-term impact on clinical and quality-of-life outcomes. ${ }^{21-23}$ One trial did document a benefit of a strength-and-endurance exercise program on long-term electromygraphic measures of back-muscle fatiguability in patients who underwent microdiscectomy. ${ }^{24}$ The authors of systematic reviews have, however, concluded that the evidence for the benefit of such supervised physiotherapy programs is of low quality $^{14,15,25}$ and that one physiotherapy approach is not super- ior to another. ${ }^{16}$ The benefit of exercise as a personal and regular practice, as opposed to a regimen intiated and overseen by a medical professional, among patients who have undergone spinal surgery is not well understood.

The existing literature on the role of exercise in the trajectory of recovery after spinal surgery is limited to small samples and low-level evidence. ${ }^{18,25}$ Exercise stress-testing has been used as an indicator of baseline functional status and surgical outcome in patients with lumbar spinal stenosis. ${ }^{19}$ Exercise intervention studies have not, however, demonstrated the long-term impact of exercise on patients who have undergone spinal decompression surgery, ${ }^{21}$ but they have suggested that the supervised introduction of aggressive exercise may reduce disability and pain after lumbar discectomy ${ }^{22}$ and may speed the attainment of recovery milestones after lumbar fusion surgery. ${ }^{23}$ Much of the existing evidence on exercise in orthopedic patients comes from studies with small sample sizes, ${ }^{24,26-28}$ which limited their ability to detect exercise benefits. ${ }^{28}$ In other orthopedic subspecialties, the benefits of the preoperative practice of exercise with respect to the trajectory of outcome have been studied. A systematic review of a small number of clinical trials suggested that exercise may be beneficial after total hip arthroplasty, although there was insufficient evidence to support specific recommendations. ${ }^{29}$

Spinal surgeons promote the concept of maintaining activity when advising patients with back pain, but they may often advise against activity out of fear of doing harm. Given the multifaceted potential benefits of exercise, the present study sought to evaluate the impact of exercise practice, before and after surgery, on the long-term outcomes of spine surgery in a robust clinical sample.

\section{Methods}

\section{Sample and design}

This longitudinal study included adults who were recruited from 4 active spine surgery practices from an academic teaching hospital. Eligibility criteria included 
being older than 18 years and having a diagnosis of a degenerative lumbar spinal disorder of disc herniation, neurogenic claudication, degenerative spondylolisthesis or lytic spondylolisthesis. The surgical indication was leg pain with or without back pain. Exclusion criteria were having had a prior lumbar surgery at the same level and not being able to understand English surveyrelated documents. Surgery was electively planned. The patient needed to be competent to complete selfreported questionnaires.

Eligible patients were recruited consecutively by the clinical research assistants, and study participation was thoroughly explained. All patients provided written informed consent before completing any questionnaires. Data were collected online or by mail at presurgery (up to 2 baselines; i.e., up to 2 presurgical survey assessments) and at 6 weeks, 3 months, 6 months and 12 months after surgery using a secure interface compliant with the Health Insurance Portability and Accountability Act (Alchemer). The study was reviewed and approved by the Sunnybrook Research Ethics Board.

\section{Measures}

The Medical Outcomes Study 36-Item Short-Form Survey (Rand-36) ${ }^{30}$ was used to assess physical and emotional functioning via the physical and mental component scores (PCS and MCS, respectively). Spine-specific disability was measured using the 10-item Oswestry Disability Index (ODI). ${ }^{31}$ Pain impact was measured using 4 Numeric Rating Scale (NRS) items to assess pain at rest, pain with activity, back pain and leg pain ${ }^{32}$ and using the 6-item Patient-Reported Outcome Measurement Information System (PROMIS) Pain Interference Short Form. ${ }^{33}$ To facilitate interpretation of the patientreported outcome (PRO) measures, all were scored such that high scores reflect better functioning; that is, ODI, NRS and PROMIS Pain Interference scores were recoded to achieve this interpretation.

Demographic characteristics were included for descriptive purposes and to serve as control variables.

Exercise practice was determined on the basis of patient responses to questions at baseline and over the course of follow-up about the frequency of musclestrength exercises, nonstop aerobic activity, and yoga or Pilates. Response options (coded item score) included not allowed (0), rarely or never (1), 1-2 times per week (2), and 3 or more times per week (3). The exercise score was a summation of the patient's responses to the 3 questions, with a possible total score ranging from 0 to 9 .

\section{Statistical analysis}

Random effects models ${ }^{34}$ were used to investigate the relationship between exercise and follow-up time on
PRO scores over time, before and after adjusting for education level and employment status. Analyses were conducted on the subsample of patients with at least 2 follow-up records. Dependent variables (PROs) were standardized for use in multivariable analysis (mean 50, standard deviation [SD] 10) to facilitate comparison of parameter estimates. Study identification was treated as a random effect, while exercise, time, their interaction, and covariates were treated as fixed effects. We began by testing simple main effects of exercise and time in predicting PRO scores over time and then added the exercise-by-time interactions. We then adjusted the main effects and interaction models for covariates (education, employment status). Final models were selected on the basis of a type I error rate of 0.05 . Stata release 15 (StataCorp LLC) and SPSS version 26 (IBM) were used for the analyses.

\section{Results}

The surgical indication was leg pain with or without back pain. Table 1 shows the distribution of diagnoses and primary procedures, as well as the demographic characteristics of the sample. A total of 168 patients had at least 2 follow-up records and were included in the analysis. The study patients had a mean age of 60.59 (SD 16.12) years and there were an equal number of men and women. They had an average of 1.90 comorbidities (range 0-6), with the most common being hypertension and osteoarthritis. The majority of the patients had more than a college degree, and about one-third were employed. Less than $5 \%$ reported being on workers' compensation currently or in the recent past.

Table 2 shows descriptive statistics for the exercise items and total score and for the PRO scores. It is notable that most of the patients either were not allowed to or chose not to engage in the exercise types assessed at baseline. Indeed, only $37 \%(n=62)$ engaged at least once a week in muscle-strength training, 29\% $(n=49)$ in aerobic exercise and $9 \%(n=15)$ in yoga or Pilates. In response to a question asking "Do you usually walk or bicycle to work?" $8 \%$ of patients $(n=13)$ responded that they usually walk to work; none indicated that they usually bicycle to work. PRO scores indicated very low physical and slightly low mental functioning at baseline, as well as high pain levels and spine-specific disability.

\section{Association between exercise, time and patient-reported outcomes}

Random effects models revealed modest but statistically significant main effects of exercise and time on PCS, MCS, PROMIS Pain Interference and ODI scores (Table 3). There were significant exercise-by-time interactions in predicting the MCS and the ODI 
Table 1 (part 1 of 2). Sociodemographic characteristics of study participants

\begin{tabular}{|c|c|}
\hline Variable & $\begin{array}{l}\text { No. }(\%)^{*} \\
n=168+\end{array}$ \\
\hline Age, $y r$, mean $\pm S D$ (range) & $60.59 \pm 16.12(18-91)$ \\
\hline No. of comorbidities, mean \pm SD (range) $\ddagger$ & $1.90 \pm 1.48(0-6)$ \\
\hline Body mass index, mean $\pm \mathrm{SD}$ (range)§ & $28.54 \pm 5.34(17-40)$ \\
\hline Follow-up time, d, mean \pm SD (range) & $255 \pm 117(41-595)$ \\
\hline \multicolumn{2}{|l|}{ Sex } \\
\hline Male & $84(50)$ \\
\hline Female & $84(50)$ \\
\hline Missing & 0 \\
\hline \multicolumn{2}{|l|}{ Primary diagnosis(es) $\uparrow$} \\
\hline Disc herniation & $60(36)$ \\
\hline Radiculopathy, sciatica & $25(15)$ \\
\hline Spinal stenosis with neurogenic claudication & $108(64)$ \\
\hline Spondylolisthesis (lytic or NOS) & $8(5)$ \\
\hline Spondylolisthesis (degenerative) & $36(21)$ \\
\hline Scoliosis, deformity & $8(5)$ \\
\hline \multicolumn{2}{|l|}{ Primary procedure $(s)^{* *}$} \\
\hline Laminectomy & $91(54)$ \\
\hline Discectomy & $102(61)$ \\
\hline Fusion & $52(31)$ \\
\hline Laminectomy and discectomy & $59(35)$ \\
\hline Laminectomy and fusion & $24(14)$ \\
\hline Discectomy and fusion & $10(6)$ \\
\hline \multicolumn{2}{|l|}{$\begin{array}{l}\text { Specific comorbidities } \\
\text { back pain excluded) } \uparrow\end{array}$} \\
\hline Anemia or other blood disease & $4(2)$ \\
\hline Cancer & $8(5)$ \\
\hline Depression & $14(8)$ \\
\hline Diabetes & $12(7)$ \\
\hline Heart disease & $15(9)$ \\
\hline Hypertension & $46(27)$ \\
\hline Kidney disease & $1(1)$ \\
\hline Liver disease & $1(1)$ \\
\hline Lung disease & $7(4)$ \\
\hline $\begin{array}{l}\text { Osteoarthritis, } \\
\text { degenerative arthritis }\end{array}$ & $45(27)$ \\
\hline Rheumatoid arthritis & $12(7)$ \\
\hline Ulcer or stomach disease & $3(2)$ \\
\hline Other & $49(29)$ \\
\hline \multicolumn{2}{|l|}{ Marital status } \\
\hline Married & $111(70)$ \\
\hline Widowed & $8(5)$ \\
\hline Living with significant other & $10(6)$ \\
\hline Single (never married) & $17(11)$ \\
\hline Divorced or separated & $11(7)$ \\
\hline Civil union or domestic partner & $1(1)$ \\
\hline Missing & 10 \\
\hline \multicolumn{2}{|l|}{ Race } \\
\hline American Indian or Alaskan Native & $1(1)$ \\
\hline Asian & $6(4)$ \\
\hline Black or African-American & $1(1)$ \\
\hline Native Hawaiian or other Pacific Islander & $0(0)$ \\
\hline White & $153(95)$ \\
\hline Missing & 7 \\
\hline
\end{tabular}

Table 1 (part 2 of 2). Sociodemographic characteristics of study participants

\begin{tabular}{|c|c|}
\hline Variable & $\begin{array}{l}\text { No. }(\%)^{*} \\
n=168 \dagger\end{array}$ \\
\hline \multicolumn{2}{|l|}{ Education } \\
\hline Less than high school & $8(6)$ \\
\hline Graduated from high school or GED & $23(16)$ \\
\hline Some college or technical school & $31(22)$ \\
\hline Graduated from college & $42(30)$ \\
\hline Postgraduate school or degree & $38(27)$ \\
\hline Missing & 26 \\
\hline \multicolumn{2}{|l|}{ Employment status } \\
\hline Working & $48(29)$ \\
\hline On leave of absence & $8(5)$ \\
\hline Retired (not because of ill health) & $52(31)$ \\
\hline Disabled or retired because of ill health & $7(4)$ \\
\hline Homemaker & $5(3 \%)$ \\
\hline Unemployed & $4(2)$ \\
\hline Student & $2(1)$ \\
\hline Other & $10(6)$ \\
\hline Not working & $32(19)$ \\
\hline \multicolumn{2}{|l|}{ Smoking status } \\
\hline Never smoked or used tobacco & $80(50)$ \\
\hline Used to smoke or use tobacco & $68(43)$ \\
\hline Currently smoke or use tobacco & $12(8)$ \\
\hline Missing & 8 \\
\hline \multicolumn{2}{|l|}{ Legal actiont } \\
\hline Not considering any legal action & $165(98)$ \\
\hline My legal action is pending & $2(1)$ \\
\hline $\begin{array}{l}\text { My legal action has been resolved in my } \\
\text { favour }\end{array}$ & $1(1)$ \\
\hline \multicolumn{2}{|l|}{ Workers' compensation status } \\
\hline $\begin{array}{l}\text { I am not planning to apply for workers' } \\
\text { compensation }\end{array}$ & 161 (96) \\
\hline I used to receive it, but do not now & $0(0)$ \\
\hline I am planning to apply for it & $1(1)$ \\
\hline I have applied for it & $1(1)$ \\
\hline $\begin{array}{l}\text { I am currently receiving workers' } \\
\text { compensation }\end{array}$ & $5(3)$ \\
\hline \multicolumn{2}{|c|}{$\begin{array}{l}\text { GED = General Education Development test (alternative to high-school diploma); NOS = } \\
\text { not specified; } \mathrm{SD}=\text { standard deviation. }\end{array}$} \\
\hline \multicolumn{2}{|l|}{ *Unless indicated otherwise. } \\
\hline \multicolumn{2}{|l|}{ tUnless indicated otherwise. } \\
\hline \multicolumn{2}{|c|}{$\ddagger n=114$. Patients were presented with a list of 14 options for comorbidities. } \\
\hline \multicolumn{2}{|l|}{$\S n=159$} \\
\hline \multicolumn{2}{|c|}{$\begin{array}{l}\text { IA nonresponse was counted as the absence of the event in question (no disease, not } \\
\text { working, no legal action, etc.). } \\
{ }^{* *} \text { Numbers may sum to areater than } 100 \% \text { because more than } 1 \text { may apply }\end{array}$} \\
\hline${ }^{* *}$ Numbers may sum to greater than $100 \%$ becaus & 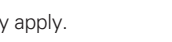 \\
\hline
\end{tabular}

trajectories in these unadjusted models (Appendix 1, available at canjsurg.ca/010620-a1). When full models were adjusted for education and employment status, interaction effects were no longer significant (Appendix 1), but the main effect of exercise remained significant for the ODI (Table 3 and Appendix 1). The main effect of time remained significant for all of the PROs (Table 3).

Figure 1 illustrates associations with exercise, with and without covariate adjustment. According to common criteria, ${ }^{35}$ the effect size was "small" in the 


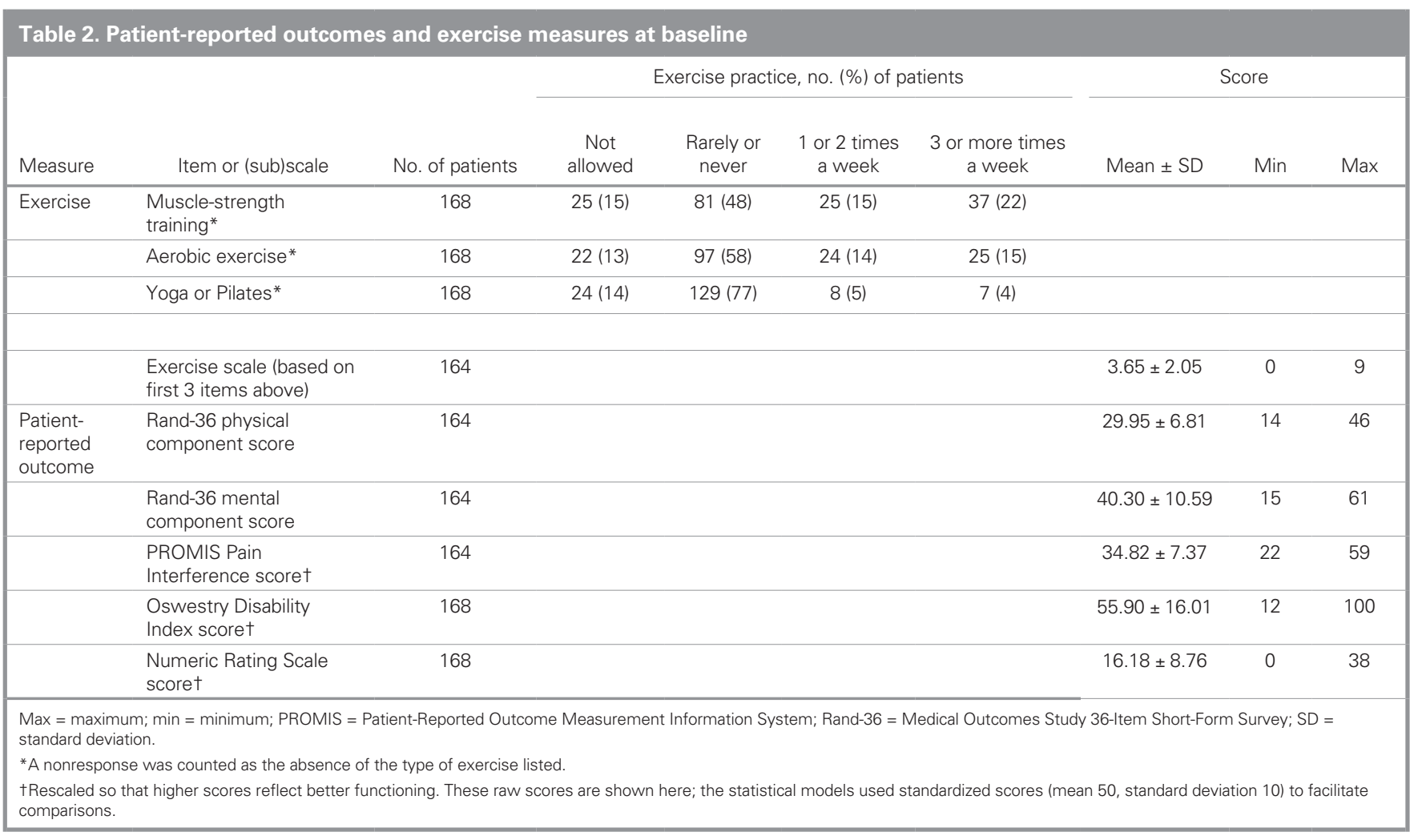

unadjusted and adjusted models predicting the ODI score, in the unadjusted model predicting the PCS score and (arguably) in the adjusted model predicting the MCS score. It did not meet the common threshold for "small" in predicting the other spine outcomes. The following illustrates the strength of the largest effect: the adjusted exercise coefficient on an ODI score of 0.78 suggests that the 2 -step difference between aerobic exercise categories "rarely or never" and " 3 or more times per week" implies an ODI score difference of 1.6 points, where the standardized mean ODI score is 50 and the SD is 10 .

These analyses suggest that the links between exercise and outcomes could also be explained by education and employment status. We thus examined how the available demographic characteristics predicted exercise practice by computing separate random effects models testing demographic predictors separately after adjusting for time and predicting the exercise score. The results revealed that people who were male, currently working and younger were more likely to exercise (Table 4).

\section{Discussion}

Results of the present study suggest that exercise and time since surgery are associated with improved outcomes in models not adjusted for sociodemographic covariates. When the models were adjusted for sociodemographic covariates, only spine-specific disability and mental health trajectories showed a beneficial link with exercise. A similar pattern occurred with models evaluating the differential effect of exercise on time to improved mental health and spine-specific disability outcomes (i.e., exercise-by-time interactions). Rather than seeing these findings as undermining the role of exercise, we wonder whether a propensity to exercise may be bundled with other salutogenic characteristics. For example, people who exercise may be more likely to be disciplined, may have better executive functioning, may be more likely to listen to their doctor or may be more likely to engage in better health behaviours such as following a healthy diet and not smoking. We did find that some patient subgroups may be more likely to exercise (men, patients who are currently working and younger patients). Surgeons cannot influence a patient's sex, employment status or age, but they can encourage patients to engage in exercise as a lifestyle choice. This would be a worthwhile focus of the provider-patient encounter.

Although there is a strong theoretical basis to support the implementation of an exercise protocol, the variability in its benefits described by PROs after lumbar spine surgery suggests that the effects of physical activity as an intervention for chronic low back pain are complex and may depend on several factors such as timing, duration and type of exercise. As there is insufficient evidence to suggest the use of one form of 
Table 3. Results of longitudinal random effects models evaluating main effects, without and with covariate adjustment

\begin{tabular}{|c|c|c|c|c|c|c|}
\hline \multirow[b]{2}{*}{ Predictor or covariate } & \multicolumn{3}{|c|}{ Without covariate adjustment } & \multicolumn{3}{|c|}{ With covariate adjustment } \\
\hline & $b$ & SE & $p$ value & $b$ & SE & $p$ value \\
\hline \multicolumn{7}{|l|}{$\begin{array}{l}\text { Rand-36 physical } \\
\text { component score }\end{array}$} \\
\hline Time & 0.022 & 0.002 & $<0.001$ & 0.019 & 0.003 & $<0.001$ \\
\hline Exercise score & 0.600 & 0.186 & 0.001 & 0.31 & 0.35 & 0.37 \\
\hline \multicolumn{7}{|l|}{ Education } \\
\hline Some college & & & & -0.48 & 2.08 & 0.82 \\
\hline College & & & & 3.62 & 1.89 & 0.06 \\
\hline Postgraduate & & & & 2.14 & 1.95 & 0.27 \\
\hline \multicolumn{7}{|l|}{ Employment } \\
\hline Currently working & & & & 6.73 & 1.73 & $<0.001$ \\
\hline Retired & & & & -1.15 & 1.76 & 0.51 \\
\hline \multicolumn{7}{|l|}{$\begin{array}{l}\text { Rand-36 mental } \\
\text { component score }\end{array}$} \\
\hline Time & 0.009 & 0.002 & $<0.001$ & 0.004 & 0.003 & 0.16 \\
\hline Exercise score & 0.367 & 0.172 & 0.033 & 0.46 & 0.37 & 0.21 \\
\hline \multicolumn{7}{|l|}{ Education } \\
\hline Some college & & & & 6.96 & 2.29 & $<0.001$ \\
\hline College & & & & 3.67 & 2.09 & 0.08 \\
\hline Postgraduate & & & & 5.62 & 2.15 & 0.01 \\
\hline \multicolumn{7}{|l|}{ Employment } \\
\hline Currently working & & & & 0.62 & 1.85 & 0.74 \\
\hline Retired & & & & 7.06 & 1.89 & $<0.001$ \\
\hline \multicolumn{7}{|l|}{$\begin{array}{l}\text { PROMIS Pain } \\
\text { Interference score* }\end{array}$} \\
\hline Time & 0.030 & 0.002 & $<0.001$ & 0.026 & 0.003 & $<0.001$ \\
\hline Exercise score & 0.376 & 0.182 & 0.039 & 0.35 & 0.31 & 0.26 \\
\hline \multicolumn{7}{|l|}{ Education } \\
\hline Some college & & & & 1.13 & 1.76 & 0.52 \\
\hline College & & & & 2.81 & 1.60 & 0.08 \\
\hline Postgraduate & & & & 1.37 & 1.65 & 0.40 \\
\hline \multicolumn{7}{|l|}{ Employment } \\
\hline Currently working & & & & 1.34 & 1.50 & 0.37 \\
\hline Retired & & & & 1.27 & 1.51 & 0.40 \\
\hline \multicolumn{7}{|l|}{$\begin{array}{l}\text { Oswestry Disability } \\
\text { Index score* }\end{array}$} \\
\hline Time & 0.027 & 0.002 & $<0.001$ & 0.023 & 0.003 & $<0.001$ \\
\hline Exercise score & 0.584 & 0.163 & $<0.001$ & 0.78 & 0.29 & 0.01 \\
\hline \multicolumn{7}{|l|}{ Education } \\
\hline Some college & & & & 2.65 & 1.76 & 0.13 \\
\hline College & & & & 3.93 & 1.61 & 0.01 \\
\hline Postgraduate & & & & 2.56 & 1.65 & 0.12 \\
\hline \multicolumn{7}{|l|}{ Employment } \\
\hline Currently working & & & & 4.65 & 1.47 & $<0.001$ \\
\hline Retired & & & & 4.23 & 1.48 & $<0.001$ \\
\hline \multicolumn{7}{|c|}{ Numeric Rating Scale* } \\
\hline Time & 0.030 & 0.002 & $<0.001$ & 0.024 & 0.003 & $<0.001$ \\
\hline Exercise score & -0.016 & 0.182 & 0.93 & 0.21 & 0.32 & 0.51 \\
\hline \multicolumn{7}{|l|}{ Education } \\
\hline Some college & & & & 1.73 & 1.88 & 0.36 \\
\hline College & & & & 2.81 & 1.72 & 0.10 \\
\hline Postgraduate & & & & 3.23 & 1.76 & 0.07 \\
\hline \multicolumn{7}{|l|}{ Employment } \\
\hline Currently working & & & & 0.07 & 1.58 & 0.96 \\
\hline Retired & & & & 0.12 & 1.59 & 0.94 \\
\hline
\end{tabular}




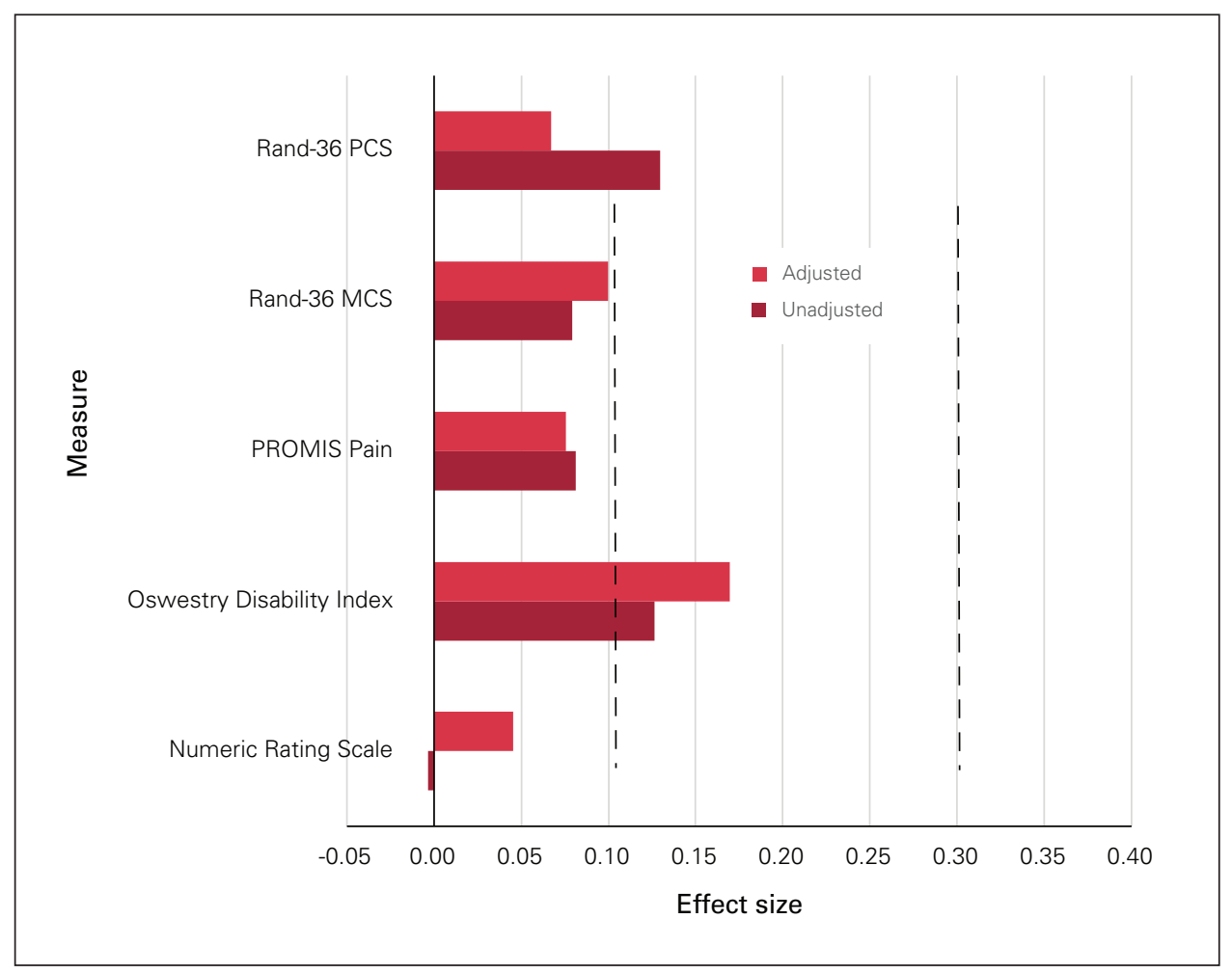

Fig. 1. Exercise effect size on outcomes, unadjusted and adjusted. MCS = mental component score; PCS $=$ physical comonent score; PROMIS Pain $=6$-item Patient-Reported Outcome Measurement Information System (PROMIS) Pain Interference Short Form; Rand-36 = Medical Outcomes Study 36-Item Short-Form Survey.

\begin{tabular}{|c|c|c|c|c|}
\hline Predictor or covariate & Coefficient & SE & $z$ & $P>|z|$ \\
\hline $\begin{array}{l}\text { Sex }(\text { male }=1 \\
\text { female }=2)\end{array}$ & -0.01 & 0.00 & -1.74 & 0.08 \\
\hline Comorbidities & 0.09 & 0.12 & 0.72 & 0.47 \\
\hline Married & 0.16 & 0.24 & 0.67 & 0.50 \\
\hline \multicolumn{5}{|l|}{ Education } \\
\hline Some college & -0.44 & 0.28 & -1.57 & 0.12 \\
\hline College graduate & 0.08 & 0.25 & 0.30 & 0.76 \\
\hline Postgraduate & 0.23 & 0.25 & 0.89 & 0.37 \\
\hline \multicolumn{5}{|l|}{ Employment status } \\
\hline Currently working & 0.76 & 0.28 & 2.73 & 0.01 \\
\hline Retired & 0.17 & 0.28 & 0.58 & 0.56 \\
\hline \multicolumn{5}{|l|}{ Smoking } \\
\hline Used to smoke & -0.24 & 0.20 & -1.18 & 0.24 \\
\hline Currently smoke & -0.22 & 0.37 & -0.59 & 0.56 \\
\hline Age & -0.34 & 0.15 & -2.23 & 0.03 \\
\hline $\mathrm{SE}=$ standard error. & & & & \\
\hline
\end{tabular}

exercise over another, a more patient-tailored approach is recommended. ${ }^{36}$ Exercise is not appropriate for patients with certain spinal conditions, such as acute disc herniations with severe sciatica. Nerve root irritations are associated with different levels of impairment with acute to chronic sciatica symptoms. The patient with an acute disc injury may not be able to exercise but the patient with a more chronic disc herniation may have tolerance limitations and be able to exercise to some extent. The patients in our study sample would be more in the latter category, as patients with spinal stenosis may also feel pain with walking beyond a particular distance. Our results indicate that exercise within the patient's tolerance limitations is beneficial for surgical outcome, and surgeons should encourage this rather than prescribing complete rest.

Furthermore, it is worth noting that the psychosocial effects of chronic low back pain, such as fear-avoidance behaviours, kinesiophobia and anxiety, should be taken into consideration as a potential barrier to physical activity when trying to encourage patients to implement exercises before and after surgery. ${ }^{37}$ There is some evidence to suggest that a combination of exercise and cognitive-behavioural therapy when implemented within the first month after surgery is more effective at reducing disability and improving health-related quality of life measures than exercise alone. ${ }^{38,39}$ In addition, although preoperative fear of movement has not been found to be predictive of poorer surgical outcomes, postoperative fear of movement was independently associated with increased postoperative pain intensity and disability. ${ }^{40}$ 


\section{Limitations}

Although our sample is of robust size and we followed participants sufficiently after lumbar spinal surgery to enable a meaningful assessment of the connection between exercise and spine outcomes, the limitations of the study should be acknowledged. First, our study was best able to address muscle-strength training and aerobic exercise. It is unfortunate that there were too few yoga practitioners to permit subgroup analysis. Imaging research has demonstrated a preventive benefit of yoga against degenerative disc disease, ${ }^{41}$ and emerging evidence from clinical trials and observational research has suggested short-term benefits in terms of pain, ${ }^{42}$ depression and anxiety in people with chronic low back pain. ${ }^{43}$ There is some imaging evidence of longer term disc and vertebral changes in patients with lower back pain who participated in a yoga intervention. ${ }^{44}$ Future research might address the impact of encouraging a 3 -pronged exercise routine (encouraging muscle-strength training, aerobic exercise and yoga) in this patient population as soon after spine surgery as is deemed safe by their physician. A second limitation is that we could not control for unmeasured factors that are associated with patient preferences to engage in exercise. It is possible that the benefit of exercise after spine surgery is confounded with the aforementioned "bundle" of unmeasured factors.

\section{Conclusion}

Our study of patients undergoing spine surgery indicates a benefit of exercise practice (strength training, aerobic exercise, yoga or Pilates) that is maintained preoperatively and as tolerated throughout follow-up (within procedure-specific limitations). People who maintain their exercise may experience more rapid improvements in their mental health and spinespecific disability, although such benefits may be dependent on other bundled characteristics. These findings support encouraging patients to engage in exercise to the extent they can and helping them reduce barriers to this salutogenic practice. This study is the first level-2 evidence demonstrating the beneficial effect of a patient's personal exercise practice maintained preoperatively and continuing as tolerated postoperatively. Surgeons and other health care providers should be educated to avoid discouraging patients from exercising while they are awaiting spine surgery. Disseminating this information widely will facilitate optimal spine surgery outcomes in many domains. This is particularly relevant given the long surgical waiting lists and unexpected delays that have occurred during the COVID-19 pandemic.
Acknowledgements: The authors are grateful to Monica Kunz and Katrine Milner for assistance in implementing the data collection for this project.

Affiliations: From the DeltaQuest Foundation, Inc., Concord, Mass., (Schwartz, Stark); the Departments of Medicine and Orthopaedic Surgery, Tufts University School of Medicine, Boston, Mass. (Schwartz); and the Division of Orthopedic Surgery, Sunnybrook Health Sciences Centre, Toronto, Ont. (Balasuberamaniam, Shrikumar, Wasim, Finkelstein).

Financial disclosure: This work was funded by the Feldberg Chair in Spinal Research, Sunnybrook Health Sciences Centre.

\section{Competing interests: None declared.}

Contributors: C. Schwartz and J. Finkelstein designed the study. C. Schwartz, P. Balasuberamanian, M. Shrikumar and A. Wasim acquired the data, which D. Schwartz, R. Stark and J. Finkelstein analyzed. C. Schwartz wrote the manuscript, which all authors critically revised. All authors gave final approval of the version to be published.

Content licence: This is an Open Access article distributed in accordance with the terms of the Creative Commons Attribution (CC BY-NC-ND 4.0) licence, which permits use, distribution and reproduction in any medium, provided that the original publication is properly cited, the use is noncommercial (i.e., research or educational use), and no modifications or adaptations are made. See: https://creativecommons.org/licenses/by-nc-nd/4.0/

\section{References}

1. Penedo FJ, Dahn JR. Exercise and well-being: a review of mental and physical health benefits associated with physical activity. Curr Opin Psychiatry 2005;18:189-93.

2. Naci H, Ioannidis JP. Comparative effectiveness of exercise and drug interventions on mortality outcomes: metaepidemiological study. BMF 2013;347:f5577.

3. King AC, Taylor CB, Haskell WL. Effects of differing intensities and formats of 12 months of exercise training on psychological outcomes in older adults. Health Psychol 1993;12:292.

4. Schwartz CE, Rapkin BD, Healy BC. Reserve and reservebuilding activities research: key challenges and future directions. BMC Neurosci 2016;17:62.

5. Schwartz CE, Zhang J, Stucky BD, et al. Is the link between socioeconomic status and resilience mediated by reserve-building activities? Mediation analysis of web-based cross-sectional data from chronic medical illness patient panels. BMF Open 2019;9:e025602.

6. Schwartz CE, Quaranto BR, Healy BC, et al. Cognitive reserve and symptom experience in multiple sclerosis: a buffer to disability progression over time? Arch Phys Med Rehabil 2013;94:1971-81.

7. King AC, Frederiksen LW. Low-cost strategies for increasing exercise behavior: relapse preparation training and social support. Behav Modif 1984;8:3-21.

8. Myers J. Exercise and cardiovascular health. Circulation 2003; $107: \mathrm{e} 2-5$.

9. Colcombe S, Kramer AF. Fitness effects on the cognitive function of older adults: a meta-analytic study. Psychol Sci 2003;14:125-30.

10. Emery CF, Schein RL, Hauck ER, et al. Psychological and cognitive outcomes of a randomized trial of exercise among patients with chronic obstructive pulmonary disease. Health Psychol 1998;17:232.

11. Guiney H, Machado L. Benefits of regular aerobic exercise for executive functioning in healthy populations. Psychon Bull Rev 2013;20:73-86.

12. Kramer AF, Erickson KI. Capitalizing on cortical plasticity: influence of physical activity on cognition and brain function. Trends Cogn Sci 2007;11:342-8.

13. Nyberg L, Lövdén M, Riklund K, et al. Memory aging and brain maintenance. Trends Cogn Sci 2012;16:292-305. 
14. Van Middelkoop M, Rubinstein SM, Kuijpers T, et al. A systematic review on the effectiveness of physical and rehabilitation interventions for chronic non spedific low back pain. Eur Spine 7 2011;20:19-39.

15. Hayden JA, van Tulder MW, Malmivaara AV, et al. Meta-analysis: exercise therapy for non specific low back pain. Ann Intern Med 2005;142:765-75.

16. Rackwitz B, de Bier R, Lim H, et al. Segmental stabilization exercises and low back pain. What is the evidence? A systematic review of randomized controlled trials. Clin Rehabil 2006;20:553-67.

17. Fors M, Enthoven P, Abbott A, et al. Effects of pre-surgery physiotherapy on walking ability and lower extremity strength in patients with degenerative lumbar spine disorder: secondary outcomes of the PREPARE randomised controlled trial. BMC Musculoskelet Disord 2019;20:468.

18. Rainville J, Hartigan C, Martinez E, et al. Exercise as a treatment for chronic low back pain. Spine f 2004;4:106-15.

19. Deen HG, Zimmerman RS, Lyons MK, et al. Use of the exercise treadmill to measure baseline functional status and surgical outcome in patients with severe lumbar spinal stenosis. Spine 1998;23:244-8.

20. Wai EK, Rodriquez S, Dagenais S, et al. Evidence-informed management of chronic low back pain with physical activity, smoking cessation and weight loss. Spine 7 2008;8:195-202.

21. McGregor AH, Doré CJ, Morris TP, et al. ISSLS Prize Winner: Function After Spinal Treatment, Exercise, and Rehabilitation (FASTER) a factorial randomized trial to determine whether the functional outcome of spinal surgery can be improved. Spine 2011;36:1711-20.

22. Danielsen JM, Johnsen R, Kibsgaard SK, et al. Early aggressive exercise for postoperative rehabilitation after discectomy. Spine 2000;25:1015-20.

23. Nielsen PR, Andreasen J, Asmussen M, et al. Costs and quality of life for prehabilitation and early rehabilitation after surgery of the lumbar spine. BMC Health Serv Res 2008;8:209.

24. Dolan P, Greenfield K, Nelson RJ, et al. Can exercise therapy improve the outcome of microdiscectomy? Spine 2000;25:1523-32.

25. Hayden JA, Van Tulder MW, Tomlinson G. Systematic review: strategies for using exercise therapy to improve outcomes in chronic low back pain. Ann Intern Med 2005;142:776-85.

26. Hando BR, Gill NW, Walker MJ, et al. Short-and long-term clinical outcomes following a standardized protocol of orthopedic manual physical therapy and exercise in individuals with osteoarthritis of the hip: a case series. 7 Manual Manip Ther 2012;20:192-200.

27. MacDonald CW, Whitman JM, Cleland JA, et al. Clinical outcomes following manual physical therapy and exercise for hip osteoarthritis: a case series. 7 Orthop Sports Phys Ther 2006; 36:588-99.
28. D'Lima DD, Colwell CW, Morris BA, et al. The effect of preoperative exercise on total knee replacement outcomes. Clin Orthop Relat Res 1996; (326):174-82.

29. Di Monaco M, Castiglioni C. Which type of exercise therapy is effective after hip arthroplasty? A systematic review of randomized controlled trials. Eur 7 Phys Rebabil Med 2013;49:893-907.

30. Hays RD, Sherbourne CD, Maze R. The RAND 36-item health survey 1.0. Health Econ 1993;2:217-27.

31. Fairbank JC, Pynsent PB. The Oswestry Disability Index. Spine 2000;25:2940-52.

32. Childs JD, Piva SR, Fritz JM. Responsiveness of the numeric pain rating scale in patients with low back pain. Spine 2005;30:1331-4.

33. Askew RL, Cook KF, Revicki DA, et al. Evidence from diverse clinical populations supported clinical validity of PROMIS pain interference and pain behavior. F Clin Epidemiol 2016;73:103-11.

34. Laird NM, Ware JH. Random-effects models for longitudinal data. Biometrics 1982;38:963-74.

35. Cohen J. A power primer. Psychol Bull 1992;112:155-9.

36. Foster NE, Anema JR, Cherkin D, et al. Prevention and treatment of low back pain: evidence, challenges, and promising directions. Lancet 2018;391:2368-83.

37. Madera M, Brady J, Deily S, et al. The role of physical therapy and rehabilitation after lumbar fusion surgery for degenerative disease: a systematic review. 7 Neurosurg Spine 2017;26:694-704.

38. Abbott AD, Tyni-Lenne R, Hedlund R. Early rehabilitation targeting cognition, behavior, and motor function after lumbar fusion: a randomized controlled trial. Spine 2010;35:848-57.

39. Monticone M, Ferrante S, Teli M, et al. Management of catastrophising and kinesiophobia improves rehabilitation after fusion for lumbar spondylolisthesis and stenosis. A randomised controlled trial. Eur Spine 7 2014;23:87-95.

40. Archer KR, Wegener ST, Seebach C, et al. The effect of fear of movement beliefs on pain and disability after surgery for lumbar and cervical degenerative conditions. Spine 2011;36:1554-62.

41. Jeng C-M, Cheng T-C, Kung C-H, et al. Yoga and disc degenerative disease in cervical and lumbar spine: an MR imaging-based case control study. Eur Spine 7 2011;20:408-13.

42. Crow EM, Jeannot E, Trewhela A. Effectiveness of Iyengar yoga in treating spinal (back and neck) pain: a systematic review. Int 7 Yoga 2015;8:3.

43. Kuvaciić G, Fratini P, Padulo J, et al. Effectiveness of yoga and educational intervention on disability, anxiety, depression, and pain in people with CLBP: a randomized controlled trial. Complement Ther Clin Pract 2018;31:262-7.

44. Telles S, Bhardwaj AK, Gupta RK, et al. A randomized controlled trial to assess pain and magnetic resonance imaging-based (MRIbased) structural spine changes in low back pain patients after yoga practice. Med Sci Monit 2016;22:3238-47. 